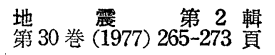

\title{
インパルス応答の推定方法とその応用
}

\author{
横浜市立大学文理学部物理教室 菊地正幸
}

(昭和 52 年 5 月 21 日受理)

\section{An Estimation Method of Impulse Response and its Application}

\author{
Masayuki KıKUCHI \\ Department of Physics, Yokohama City University
}

(Received May 21, 1977)

The estimation of linear filter from observed time series of input $x_{1}(\mathrm{t})$ and output $x_{2}(\mathrm{t})$ is considered. Following Burg's algorithm for maximum entropy method, a new technique is developed in this paper, where the impulse response of the filter as well as the correlation functions of $x_{1}$ and $x_{2}$ are simultaneously estimated.

The method is applied to the analysis of elastic wave response of rock samples (granite). It is shown that the dispersion of $\mathrm{P}$-wave phase velocity amounts to 4 percent of the nondispersive velocity. It is comparable to the value expected from the attenuation property: $\mathrm{Q}=10 \sim 20$ and Kramers-Kronig causality relation.

\section{§1.はじめに}

地球物質のQはかなり広い周波数領域にわたつて，一定であると考えられている。したがつ て, 理論記像や震源関数の推定に执いて用いられる $\mathrm{Q}$ フィルタは, この $\mathrm{Q}=$ 一定という条件 にあまり矛盾しないように作られる。ただし，その位相特性に関する情報が不足しているの で，たいていは，減衰一位相間に KRAMERS-KRÖNIG (K-K) の関係を仮定して計算される [FUTTERMAN (1962)]．こうして得られるQフィルタは，観測に十分かかるほど大きい速度分 散を示すので，たとえば室内実験とフィールドの比較において [STRICK (1970)], あるいは表 面波分散の物理的解釈に和いて [LIU et al. (1976)]，いろいろと重要な問題が生じてくる.

ところで, 減衰一位相間の $\mathrm{K}-\mathrm{K}$ 関係はあたかも応答の因果律と等価な如く扱われること が多いが, 厳密には, 応答の因果律に加えて, その逆応答の因果律をも前提条件としている，応 答の因果律は当然としても,逆応答の因果律は必ずしも物理的に必要な条件とは考えにくい.し たがつて，さしあたりは，K-K 関係の仮定とは独立な位相（分散）特性の検出により，その 適否を判定する必要がある。一般に，振幅特性に比べて位相特性の解析が困難な理由は，いわ

昭和 52 年 5 月 12 日発表 
ゆる Taper Filter とか Smoothing Filter が使えないことにある。このような Filter は, 不 可避的に, 人為的な位相を付加してしまうからである.かといつて観測される時系列に直接フ一 リエ変換を行らと，観測打ら切りの影響や観測誤差のために，まともな位相特性が得られな い。この論文では，そのような困難を克服するために，Maximum Entropy Method の考光

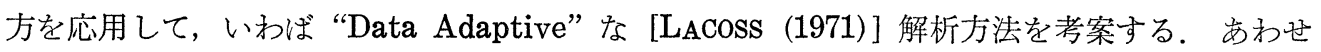
て，室内実験データに対する1つの適用例を示す。

\section{$\S 2$. 解析方法}

同一の振動源について, 距離 $L_{1}, L_{2}$ に和ける弾性波を $x_{1}(t), x_{2}(t)$ と拈く.いま, 長さ $\Delta L=L_{2}-L_{1}(>0)$ に対する弾性波のインパルス応答を $h(t)$ とおくと，系が線形である限り

$$
x_{2}(t)=h(t) * x_{1}(t)
$$

の関係が成り立つ。ただし，*はコンボリューションを示す。ここの目的は, 観測值 $x_{1}, x_{2}$ か ら $h(t)$ を推定することである。これは, 入力 $x_{1}$, 出力 $x_{2}$ から最適な線形フィルタを決定す る問題とみなせる。 以下, 実用的観点から, 関数はすべてサンプリング間隔 $\Delta t$ の時系列とし, 時刻 $t=0, \Delta t, 2 \Delta t, \cdots \cdots$ に和ける物理量 $x$ の值を, $x(0), x(1), x(2), \cdots \cdots$ のように簡略化 する。また，とくに断わらない限り，時系列はすべて $t=0$ で立ち上がるものとする。という のは，たとえばインパルス応答がある遅延時間 $t_{0} \Delta t$ をもつていたとしても， $h\left(t+t_{0}\right), x_{2}(t+$ $\left.t_{0}\right)$ をあらためて $h(t), x_{2}(t)$ と特きか光れば，遅延がない場合の理論がそのまま使光るからで ある． $h(t)$ の推定にあたり考慮すべき点は，まず，与兄らる観測值 $x_{1}(t), x_{2}(t)$ から最大 限の情報をひきだすこと，拈よび，観測打ら切りの効果をできるだけ少なくすることである。 雑音の処理がより本質的である場合も多いが，ここではそれにはふれない。

いま，有効な作用時間 $m \Delta t$ の関数 $h_{m}(t)$ で $h(t)$ を近似する。すなわち， $h_{m}(t)$ は $t<$ $0, t>m$ に対し零という制約をもつとする. 入力 $x_{1}(t)$ から推定される出力は

$$
\hat{x}_{2}(t)=\sum_{\tau=0}^{m} h_{m}(\tau) x_{1}(t-\tau) \Delta t
$$

で与えられるから，各時刻に和ける出力の推定誤差は

$$
d_{m}(t) \equiv x_{2}(t)-\hat{x}_{2}(t)=x_{2}(t)-\sum_{\tau=0}^{m} h_{m}(\tau) x_{1}(t-\tau) \Delta t
$$

となる. 与えられた条件下での最適化は，この推定誤差を入力 $\left\{x_{1}(t-s): s=0, \cdots \cdots, m\right\}$ と無 相関にすることである. (3) 式の両辺に $\sum_{t} x_{1}(t-s) \Delta t$ をかけると, $\left\{h_{m}(t): t=0, \cdots \cdots, m\right\}$ に 関する正規方程式が得られる.

$$
\sum_{\tau=0}^{m} h_{m}(\tau) r_{11}(\tau-s) \Delta t=r_{12}(s), s=0, \cdots \cdots, m
$$


ここで, $r_{11}$ は $x_{1}$ の自己相関関数:

$$
r_{11}(\tau)=\sum_{t} x_{1}(t) x_{1}(t+\tau) \Delta t
$$

であり, $r_{12}$ は $x_{1}, x_{2}$ の相互相関関数:

$$
r_{12}(\tau)=\sum_{t} x_{1}(t) x_{2}(t+\tau) \Delta t
$$

である. (4) 式をみてわかるように, インパルス応答の推定は, 結局自己相関, 相互相関の推 定に䚻着する.ここで, 観測打ち切りの処理が問題となつてくる.この影響を少なくする方法 として，BLACKMAN-TUKEY (1959) の理論に基づいた Taper Filter の応用が考劣られるが， $x_{1}(t)$ や $x_{2}(t)$ のフーリエ変換が周波数依存の位相をもつている場合には, 人為的位相を付加す ペクるという点から, また, 分解能を悪くするといら点からも好ましくない.ここでは, パワース トルの推定に最近よく用いられるようになつた Maximum Entropy Method [BURG (1972)] にならつて， $r_{11}, r_{12}, h_{m}$ を同時に推定していく方法を考案する. そのために，まずMEM の 考光方をらりか兄りながら，自己相関 $r_{11}(t)$ をを推定してみよう.

\section{$r_{11}(\boldsymbol{t})$ の推定}

$\left\{x_{1}(t-s): s=1, \cdots \cdots, m\right\}$ から $x_{1}(t)$ を予測するフィルタを $\left\{-a_{m}(t): t=1, \cdots \cdots, m\right\}$ と拉 く.このとき予測䛊差は

$$
e_{m}(t)=x_{1}(t)+\sum_{\tau=1}^{m} a_{m}(\tau) x_{1}(t-\tau) \Delta t
$$

で与えられる. $e_{m}(t)$ が $\left\{x_{1}(t-s): s=1, \cdots \cdots, m\right\}$ と無相関になるような最適フィルタを決め る方程式は，(7) 式の両辺に $\sum_{t} x_{1}(t-s) \Delta t$ をか子ることにより得られる。いま， $a_{m}(0) \Delta t=1$ と特くと，それは

$$
\sum_{\tau=0}^{m} a_{m}(\tau) r_{11}(\tau-s) \Delta t= \begin{cases}\alpha_{m} & \text { for } s=0 \\ 0 & \text { for } s=1, \cdots \cdots, m\end{cases}
$$

と表される。ただし，未知数は， $a_{m}(1), \cdots \cdots, a_{m}(m)$ ，および,

$$
\alpha_{m}=\sum_{\tau=0}^{m} a_{m}(\tau) r_{11}(\tau) \Delta t
$$

である.フィルタ $\left\{a_{m}(t): t=0, \cdots \cdots, m\right\}$ はふつう予測誤差オペレタと呼ばれ，また， $\alpha_{m}$ は予 測誤差のエネルギーに等しい。なんとなれば

$$
\begin{aligned}
\sum e_{m}(t)^{2} \Delta t & =\sum_{t} \sum_{\tau} \sum_{s} a_{m}(\tau) x_{1}(t-\tau) a_{m}(s) x_{1}(t-s) \Delta t^{3} \\
& =\sum_{\tau} \sum_{s} a_{m}(\tau) a_{m}(s) r_{11}(\tau-s) \Delta t^{2} \\
& =\alpha_{m} a_{m}(0) \Delta t=\alpha_{m}
\end{aligned}
$$

(8) 式をみたす予測誤差オペレタ $a_{m}(t)$ 抢よび $\alpha_{m}$ は， $m$ に関する次の漸化式を満足す 
る.

$$
\begin{aligned}
& a_{m}(t)=a_{m-1}(t)+u a_{m-1}(m-t) \\
& \alpha_{m}=\alpha_{m-1}\left(1-u^{2}\right)
\end{aligned}
$$

ここで, 定数 $u$ は自己相関関数と次の関係がある.

$$
\sum_{\tau=0}^{m-1} r_{11}(m-\tau) a_{m-1}(\tau) \Delta t+u \alpha_{m-1}=0
$$

一方，予測誤差 $e_{m}(t)$ ，および，

$$
f_{m}(t)=\sum_{\tau=0}^{m} a_{m}(\tau) x_{1}(t-m+\tau) \Delta t
$$

で定義される逆向きの予測誤差 $f_{m}(t)$ は, 漸化式:

$$
\begin{aligned}
& e_{m}(t)=e_{m-1}(t)+u f_{m-1}(t-1) \\
& f_{m}(t)=f_{m-1}(t-1)+u e_{m-1}(t)
\end{aligned}
$$

を満たす。いま， 入力 $x_{1}(t)$ の観測打ち切り時刻を $N \Delta t$ とすると， $e_{m}(t), f_{m}(t)$ には, $t>$ $N$ に沶いて打ち切りの影響が現れる。また， $e_{m}(t), f_{m}(t)$ は $t<0$ に执いて零となる。 これ らを考慮した上で,

$$
\sum_{i=0}^{N} e_{m}(t)^{2} \Delta t=\min
$$

の条件から，uの值を決めると

$$
u=-\sum_{i=1}^{N} e_{m-1}(t) f_{m-1}(t-1) / \sum_{t=1}^{N} f_{m-1}(t-1)^{2}
$$

となる，条件（14）は予測誤差を最小にする（すなわち情報エントロピーを最大にする）操作 を示すものであり，これが MEM という呼称の由来となつている。（15）式で $u$ が決まると， これを（11）式に代入して， $r_{11}(m)$ が求められる。すなわち

$$
r_{11}(m)=-\left(u \alpha_{m-1}+\sum_{t=1}^{m-1} r_{11}(m-t) a_{m-1}(t) \Delta t\right)
$$

初期条件として

$$
r_{11}(0)=1, \quad e_{0}(t)=f_{0}(t)=x_{1}(t)
$$

を与えれば，上の漸化式により，順に $r_{11}(1) ， r_{11}(2), \cdots \cdots$ が求められる。この場合，相関関 数は $r_{11}(0)$ で正規化されたものが得られる.

(10) 式からわかるように, 予測誤差のエネルギー $\alpha_{m}$ は $m$ とともに単調に減少する。 こ のことは単純にフィルタの長さが長いほど良いということを意味するものではない。ここで, 観測データの数 $N+1$ とオペレタの未知数 $m$ から決まる系の自由度 $N+1-m$, 拈よび, 計 算に関与している範囲の $x_{1}(t)$ の 2 乗平均を考慮しなければならない.オペレタの長さが $m$ 
のとき，暗に， $x_{1}(t)$ が $-m \leq t<0$ に抢いて零であることを仮定しているから， $x_{1}(t)$ の 2 乗平均は

$$
\sum_{t=0}^{N} x_{1}(t)^{2} \Delta t /(N+m+1)
$$

で与えられる，よつてオペレタの長さを決める目安としては，1自由度あたりの相対誤差

$$
\bar{\alpha}_{m}=\frac{\alpha_{m}}{N-m+1} / \frac{\sum_{t=0}^{N} x_{1}(t)^{2} \Delta t}{N+m+1}
$$

を用いるのが望むしい[AKAIKE (1970)]．この $\bar{\alpha}_{m}$ を最小とする $m$ の值 $(=M)$ が最適のフ ィルタの長さとなる。このとき, $\left\{r_{11}(M+\tau): \tau=1,2, \cdots \cdots\right\}$ は

$$
r_{11}(M+\tau)=-\sum_{s=1}^{M} a_{M}(s) r_{11}(M+\tau-s) \Delta t
$$

により順に求められる.

\section{$\boldsymbol{r}_{12}(\boldsymbol{t}), \boldsymbol{h}_{m}(\boldsymbol{t})$ の推定}

正規方程式 $(4)$ の $h_{m}(t)$ は， $m$ に関する淖化式:

$$
h_{m}(t)=h_{m-1}(t)+v a_{m}(m-t)
$$

を満足する [LEVINSON (1947)]．ただし定数 $v$ は $r_{12}(m)$ と

$$
\sum_{\tau=0}^{m-1} r_{11}(m-\tau) h_{m-1}(\tau) \Delta t+v \alpha_{m}=r_{12}(m)
$$

の関係をるつ.一方, 出力の推定誤差は

$$
d_{m}(t)=d_{m-1}(t)-v f_{m}(t)
$$

で与えられる. $x_{2}(t)$ の観測打ち切り時刻を $N \Delta t$ とすると， $d_{m}(t)$ に対する打ち切りの影響は $t>N$ に絲いて現れる。よつて, MEM の考えにならつて

$$
\sum_{t=0}^{N} d_{m}(t)^{2} \Delta t=\min
$$

の条件から, $v$ の值を求めると

$$
v=\sum_{t=0}^{N} f_{m}(t) d_{m-1}(t) / \sum_{t=0}^{N} f_{m}(t)^{2}
$$

となる。これを $(19) ，(20)$ 式に代入すれば， $h_{m}(t) ， r_{12}(m)$ が求められる。な特，初期条 件としては

$$
\begin{aligned}
r_{12}(0) & =\sum_{t=0}^{N} x_{1}(t) x_{2}(t) / \sum_{t=0}^{N} x_{1}(t)^{2} \\
h_{0}(0) \Delta t & =r_{12}(0), \quad d_{0}(t)=x_{2}(t)-h_{0}(0) x_{1}(t) \Delta t
\end{aligned}
$$

を用いればよいまた，インパルス応答の最良の長さを決める目安としては， $d_{m}(t)$ の 2 乗和 を, 系の自由度 $N-m$ と出力の 2 乗平均で正規化した值 


$$
\bar{\gamma}_{m}=\frac{\sum_{t=0}^{N} d_{m}(t)^{2}}{N-m} \mid \frac{\sum_{t=0}^{M} x_{2}(t)^{2}}{N+1}
$$

を用いる，この量は, インパルス応答の遅延時間, すなわち出力 $x_{2}(t)$ の立ち上がり時刻を決 定する場合の目安としても使うことができる。 こうして， $\bar{\gamma}_{m}$ を最小にするような最適の遅延 $\tau_{0}$, および, 有効作用範囲 $M^{\prime}$ をもつたインパルス応答 $\left\{h_{M^{\prime}}(t): t=0, \cdots \cdots, M^{\prime}\right\}$ が決まり,さ らに, そのフーリエ变換:

$$
H(\omega)=\sum_{t=0}^{M^{\prime}} h_{\mathbb{M}^{\prime}}(t) e^{i \omega\left(t+\tau_{0}\right) \Delta t} \Delta t
$$

により，伝達関数が計算される.

\section{§3. 岩石のたて波インパルス応答}

前節の解析方法を室内実験の記録に適用してみた. 実験のブロック図を Fig. 1 に示す. 試 料は釜石産の granite で, 径約 $4 \mathrm{~cm}$ のコアをいろいろな厚さに輪切りにしたものである. パルス発振器から, パルス幅約 $10 \mathrm{~ns}$, 振幅 $5 \mathrm{~V}$, 繰り返し 周期 $50 \mu \mathrm{s}$ の電気パルスが送ら れ，5 MHz-PZT によりたて波が励起される. 試料を通つた波は再び電気信号に変換され, 増 幅の後, サンプロスコープに入る. これにより，2 $\mu \mathrm{s}$ の時間間隔が約 $5 \mathrm{~s}$ に拡大され, 容量 $1 \mathrm{~K}$ word のディジタルメモリに記憶される：最後に，この内容は紙テープにパンチされ，計 算機（OKITAC 4300）にかけられる。なお, パルスの送信や受信系の特性が, 試料毎にで きるだけ変らないよらに，振動子，ケーブル などはすべて同一のものを使用した。

Fig. 2 に，それぞれの長さの試料につい

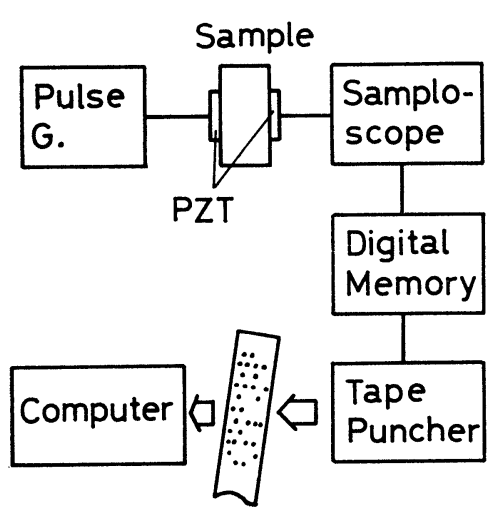

Fig. 1. Blockdiagram of experimental setup.

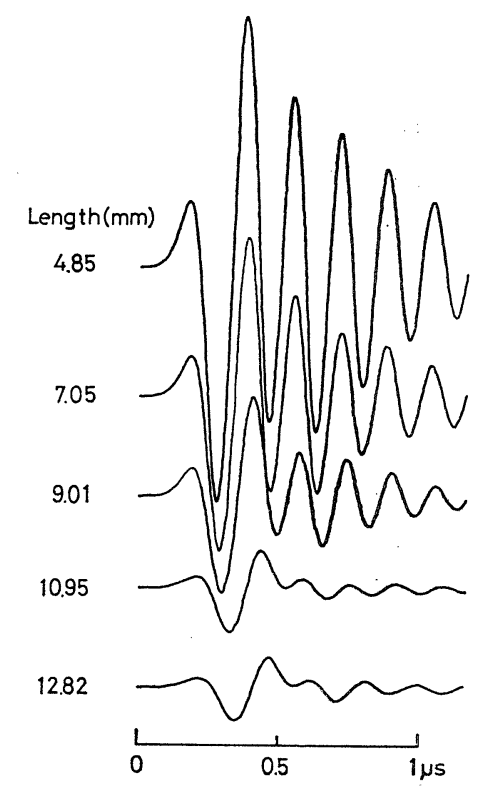

Fig. 2. Waveforms observed at various length of samples (granite). 


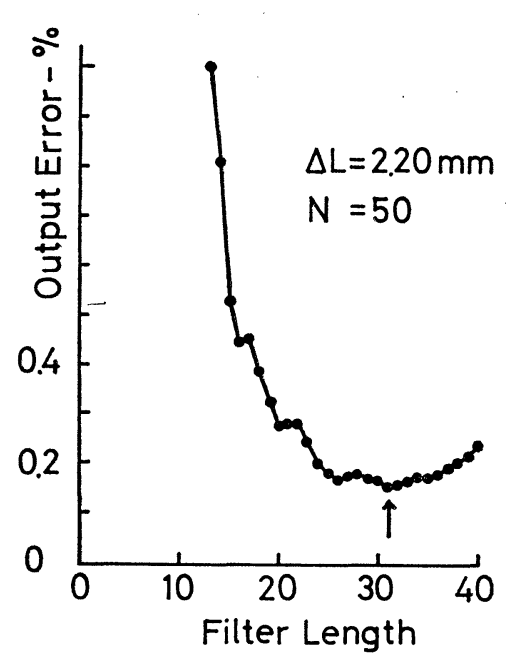

Fig. 3. An example of relative output error $r_{m}$ vs. filter length $m$. The optimum filter length is given so that the error is minimum.

て観測された波動を示す。図の範囲は各々約 500 個分のディジタルデータから成る. $L=$ $4.85 \mathrm{~mm}$ の記録を基準 (§ 2 の $x_{1}(t)$ ) にとり, それぞれの長さに対するインパルス応答を計 算した。 この場合, もとのデータの 10 ポイン

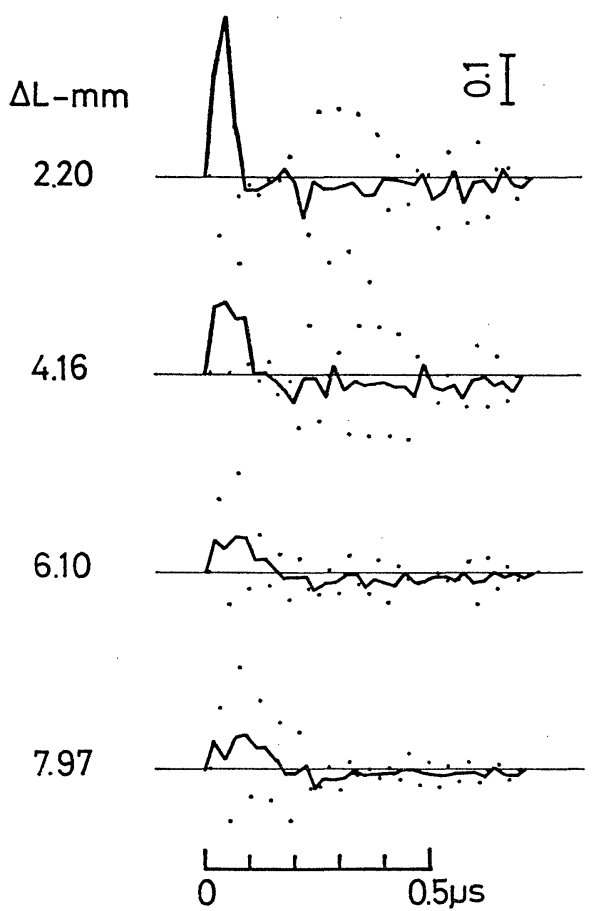

Fig. 4. Optimum impulse responses (dot) computed by the present method. Solid line shows the two-point moving average of them. Onset of each trace is shifted by the optimum delay time determined in the analysis.

ト毎の値だけを使用した。すなわち，解析に用いたデータのサンプリング間隔を実際のそれの 10倍とした。また，1つのインパルス応答の計算ごとに，最適フィルタの長さおよび遅延時間 を決めるため, 相対出力誤差 $\bar{\gamma}_{m}$ のマップを作つた。一例として, Fig. 3 に, フィルタの長 さ $m$ に対する $\bar{\gamma}_{m}$ の変化を示す。な拈，Fig.2. の波形は，このマップから決められる最適 の立ち上がり時刻を $t=0$ にそろえたものである。

こうして最終的に求められたインパルス応答を Fig. 4 に示す。点が実際に求められた值で ある、これをみてわかるよらに匡とんど1ポイント毎に正負の值をとる。これは，ナイキスト 周波数 (N.F) 付近の感度の低さを反映したものであり, 実際に意味があるのは N.F の半分 以下の領域である。このような観点から，Fig．4，飞は，2点間の移動平均を実線で示してあ る.試料の長さとともに，インパルス応答の振幅が小さくなり，パルス幅が増大していく様子 がわかる。

Fig. 5. はインパルス応答の振幅特性，Fig. 6. はその位相特性である，いずれも， N. F. 


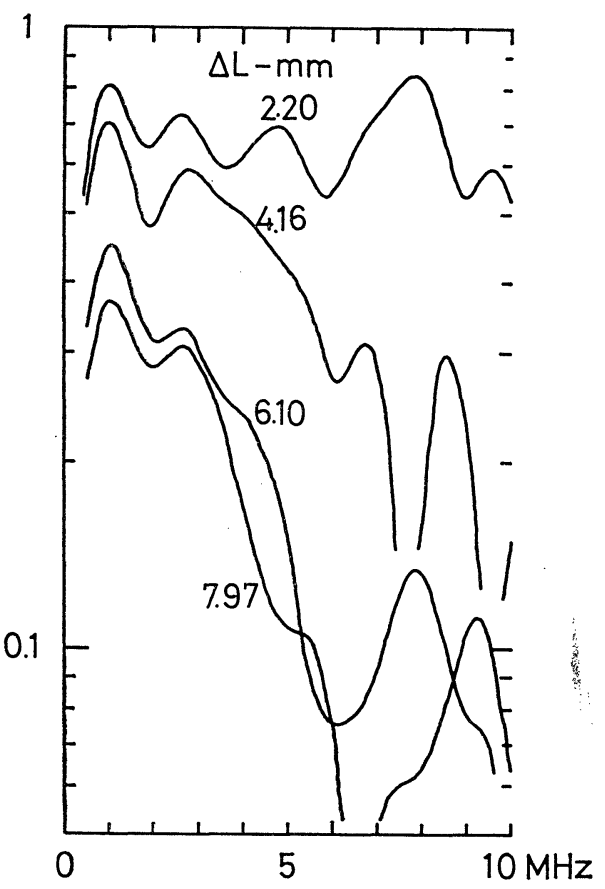

Fig. 5. Logarithm of amplitude vs. frequency of the transfer function: Fourier transform of impulse response.

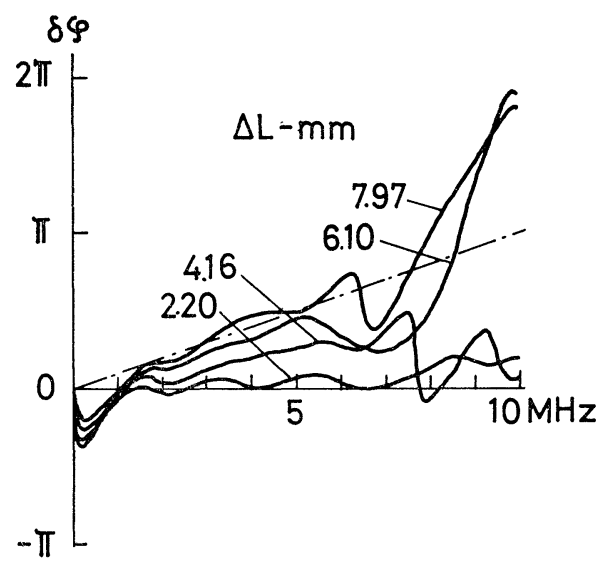

Fig. 6. Phase vs. frequency of the transfer function. Broken line shows the phase shift corresponding to $0.05 \mu$ s time delay from the onset time. A significant velocity dispersion can be seen in the frequency domain less than about $6 \mathrm{MHz}$.
の約半分以下の周波数領域を示してある。ま た，位相特性の図では，それぞれの遅延時間 $\tau_{0} \Delta t$ による位相 $\phi_{0}=2 \pi f \tau_{0} \Delta t$ 分は差し引い てある。振幅, 位相特性とも, 执よそ6 $\mathrm{MHz}$ 以下の領域では周波数に対しなめらかな変化 を示し, かつ, 長さ $\Delta L$ に関しても系統的に 勾配が変化している。これに対し，6 $\mathrm{MHz}$ り高い周波数領域では，振幅特性はがたつ き，位相は $\Delta L$ が大きくなると急に遅れが大 きくなる. $6 \mathrm{MHz}$ の波長が約 $1 \mathrm{~mm}$ であり， ほぼ試料の grain size に等しいことを考え ると，上述のような不規則性は，grain によ る散乱効果と思われる.

Table 1. Quality factor $Q$ and dispersion of $\mathrm{P}$-wave phase velocity obtained in the frequency less than $6 \mathrm{MHz}$.

\begin{tabular}{lcll}
\hline \multicolumn{1}{c}{$\Delta L$} & $Q$ & $v(6 \mathrm{MHz})-v_{0}$ & $\left|\delta v / v_{0}\right|$ \\
\hline $2.20 \mathrm{~mm}$ & $17 \sim 22$ & $-0.18 \mathrm{~km} / \mathrm{s}$ & $2.9 \%$ \\
4.16 & $15 \sim 17$ & -0.23 & 3.8 \\
6.10 & $10 \sim 15$ & -0.25 & 4.1 \\
7.97 & $10 \sim 20$ & -0.26 & 4.2 \\
\hline
\end{tabular}

Table 1. に低周波領域で推定される quality factor Q の值, 抢よび, 位相速度のずれ （分散）の割り合いを示す.抌よそ, $Q=10 \sim 20$, $\delta v / v_{0}=3 \sim 4 \%$ である. この結果は分散一位 相間の $\mathrm{K}-\mathrm{K}$ 関係から期待される值 [STRICK (1970)など〕とほぼ同程度である。ただし， $\delta v$ は立ち上がりの速度 $v_{0}(=6.13 \mathrm{~km} / \mathrm{s})$ から のずれであり，必ずしも高周波の限界速度 $v_{\infty}$ を基準にしたものではない。もちろん，この ような結果を一般的なものと断定するにはデ 一タが少なすぎる。いずれにせよ， $\mathrm{K}-\mathrm{K}$ 関 
係の仮定とは独立な位相特性の研究がもつと必要であろう。

\section{謝 辞}

$\S 2$ 解析方法においては, 東京大学理学部地球物理教室の斎藤正徳助教授との討論が大いに 役立つた。ここに感謝いたします。

$$
\text { 文献 }
$$

AKaike, H., 1970, Statistical Predictor Idetification, Ann. Inst. Statist. Math., 22, 203-217.

Blackman, R. B. and J. W. Tukey, 1959, The Measurement of Power Spectra from the Point of View of Communication Engineering, New York, Dover.

BurG, J. P., 1972, The Relationship Between Maximum Entropy Spectra and Maximum Likelihood Spectra, Geophys., 37, 375-376.

Futterman, W., 1962, Dispersive Body Waves, J. Geophys. Res., 67, 5279-5291.

LACoss, R. T., 1971, Data Adaptive Spectral Analysis Methods, Geophys., 36, 661-675.

Levinson, N., 1947, The Wiener RMS (Root Mean Square) Error Criterion in Filter Design and Prediction, J. Math. Phys., 25, 261-278.

Liv, H. P., D. L. Anderson and H. Kanamori, 1976, Velocity Dispersion due to Anelasticity; Implications for Seismology and Mantle Composition, Geophys. J. roy. Soc., 47, 41-58.

Strick, E., 1970, A Predicted Pedestal Effect for Pulse Propagation in Constant-Q Solids, Geophys., 35, 387-403. 